\title{
Revalorization of Social Reproduction through Social and Solidarity Economy Practices
}

The feminist analysis of social and solidarity economy (SSE) practices in the six cases studied in the project (see box) has found that, in the face of destructive patriarchal capitalism, SSE practices may contribute to the valorization of women's work, strengthening of social ties, and the protection of life as such. Under certain conditions, SSE practices may also contribute to the formation of political subjects capable of challenging patriarchal capitalist structures towards greater recognition and more rights. While marked with challenges, SSE practices may thus form part of collective struggles for equitable and more sustainable societies.

\section{The organization of social reproduction in capitalist societies}

The organization of productive and reproductive activities in capitalist societies gives rise to hierarchies that have long been critiqued by feminist scholarship. These hierarchies privilege the production and accumulation of capital over social reproduction, in particular men's labour over women's work, obscuring the importance of social reproductive activities for the production of life and hence for the prosperity of capitalism itself.

In this sense, these hierarchies presuppose the existence of two separate and unequal spheres, a separation that has been contested in feminist studies. One productive, predominantly associated with activities carried out by men, and another, reproductive, associated with all activities and institutions required to maintain the household and society. Historically situated within the reproductive sphere or tied closely to it, women's work within this framework has come to be valued less than men's labour, creating as a result new forms of women's subordination.

While these hierarchies are as old as capitalism itself, they nevertheless are not static. The cases studied in this project show that globalization, and modernization discourses and practices-such as urbanization, and industrialization in agriculture and other sectors-mark a profound change in female and male social relations of production and social reproduction. Several of the cases studied found changes in women's work, with tasks traditionally carried out by men, or shared by men and women, opening up to or requiring more women's participation due to decline in "traditional" industries, change in women's role in the household, and industrial and technological innovation.
Box 1: Project Overview: Feminist Analysis of Social and Solidarity Economy Practices: Views from Latin America and India

Social and solidarity economy (SSE) has a potentially important role to play in reorienting economies and societies toward more equitable, inclusive and sustainable development. But it can only be truly transformative if it also addresses the reorganization of social reproduction, integrating the political goals of gender equality and more equitable power relations. Are SSE practices moving in the right direction?

Even though women play a major role in SSE activities, until very recently the interest of both academics and policy makers in SSE has lacked a gender perspective. Feminist research on unpaid care and domestic work is only beginning to inform policy making and implementation on the ground, and SSE activities that relate to social reproduction (that is, by which society reproduces itself) are often under-recognized. The different social relationships and gender hierarchies at work in SSE typically lack a feminist analysis.

This research project aimed to contribute empirical evidence and analytical insights to begin filling these gaps in SSE research and policies from a feminist perspective.

\begin{tabular}{ll} 
& \multicolumn{1}{c}{ India case studies } \\
\hline - Karnataka: Udupi fisherwomen association \\
- Kerala: SEWA domestic workers association \\
- Kamil Nadu: Women's organizations against sand quarries in \\
Kancheepuram District, Palar Valley
\end{tabular}

Latin America case studies

- Argentina: Community organizations providing care services in suburbs of Buenos Aires

- Bolivia: Producer associations in Batallas, Department of La Paz

- Brazil: Agroecological and feminist collective production groups in Vale do Ribeira, State of São Paolo

The project was funded by the Swiss Network for International Studies (SNIS). Find more information about the project here. 
In the rural areas studied in Bolivia (Batallas) for instance, the search for non-agricultural work has led to an increase in the number of men migrating from rural to urban areas in pursuit of new opportunities. As result, agriculture and animal husbandry activities, usually carried out by both men and women, have become increasingly feminized, and the number of women participating in peasant unions and producers' associations has also increased.

Industrialization in Tamil Nadu has led to the relative feminization of industrial labour and to a change in the notion of work itself. The over-exploitation of natural resources, for instance, has led young women to move from agriculturerelated occupations into industrial ones, such as manual workers in textile, leather garment or agri-food industries, or into low-skilled services such as cleaners for private schools, which require different knowledge and skills to perform.

While such processes have expanded women's aspirations and opportunities, at least economically, the change in women's work within a space dominated by patriarchal capitalist logic has counterparts inherent in the deep structure of patriarchal capitalist societies that devalue women's economic activities. For instance, women's work is often perceived as a "service" rather than a labour. In such circumstances, women are not considered to be economic agents entitled to remuneration for their labour, or social rights, or protection and support of the state. On the contrary, their labour is perceived as a service to their families and communities by virtue of being women. "Naturalizing" women's labour in this way devalorizes women's productive activities. In this sense women's labour-care, selling fish, agricultural work, subsistence farming-joins the invisible sphere of social reproduction, rendering these economic activities analogous to domestic ones that are poorly valued and not considered as work contributing to the reproduction of life. This, in turn, "justifies" the low economic value ascribed to women's labour and the limited social protection from which women benefit.

Such perceptions and processes did not emerge in a vacuum. Feminist analysis finds them to be the product of the hierarchies embedded in capitalist societies. In this sense, female and male roles in production and social reproduction are typically regarded as a matter of fact, and not as an issue that requires analysis, public action and ultimately change. This, in turn, explains to some extent the limited institutional recognition of women's work, as well as the gendered worldviews that predominantly characterize the public policies and programmes put in place to support and empower women.

In the case of the rural region of Vale do Ribeira (Brazil) for instance, the value of motherhood occupies a central place in the social representation of women and in public policies. This is reflected, for example, in the discourses of social workers in the region studied and in the conditionalities associated with Bolsa Familia, a nationwide cash transfer programme, in which mothers are responsible for their chil- dren's school attendance and vaccination in order to receive benefits. Furthermore, the training programmes for women beneficiaries of the Bolsa Familia tend to push women into presumed "female" activities such as beauty, fashion and cooking (while ignoring agriculture), reinforcing as such the existing sexual division of labour that gender inequality is based upon.

In Kerala, India, domestic work performed by women tends to be seen as an extension of the housework that housewives anyway perform as part of their duties as women. As a result of such perceptions, domestic workers are poorly valued (remunerated), poorly regulated, and largely left out of the purview of conventional labour laws.

Similar patterns and processes were also observed in the government support for women's associations in the case study in Argentina. Microfinance and government subsidies for social economy organizations, for instance, tend to exclude collective care services, and where support does exist, care workers tend to be poorly remunerated. This gendered perception of care work highlights the productive bias of public policies for SSE, which place reproductive activities in a secondary position.

This lack of recognition of women's work, whether agriculture, domestic, care or other work, has severe implications for women's lives and well-being. Women's engagement in precarious, poorly remunerated jobs with limited protection and rights makes them susceptible to exploitation and subsequently increases their vulnerabilities and dependency. The case studies found that due to unequal division of labour, inadequate social and care services, and persistent poverty, women are exhausted: they lack sleep, and are developing health problems early on. The pressures of juggling productive and reproductive activities also mean that women have limited spare time for leisure, or for social mobilization. This may ultimately restrict their ability to get involved and participate in alternative political or social movements that strive to meet their needs, but also to change underlying structural conditions.

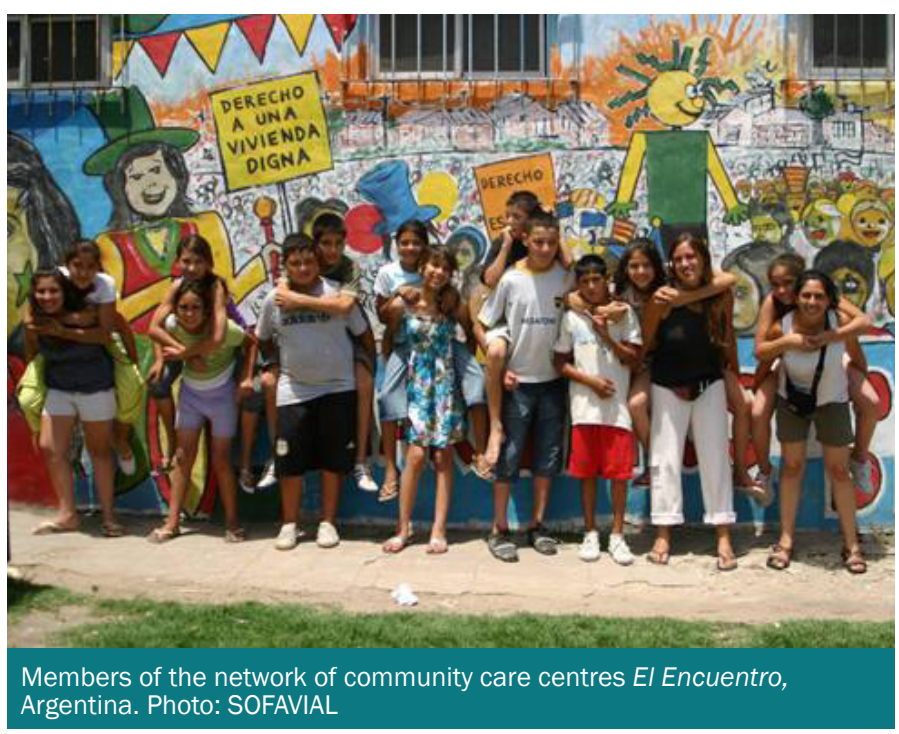




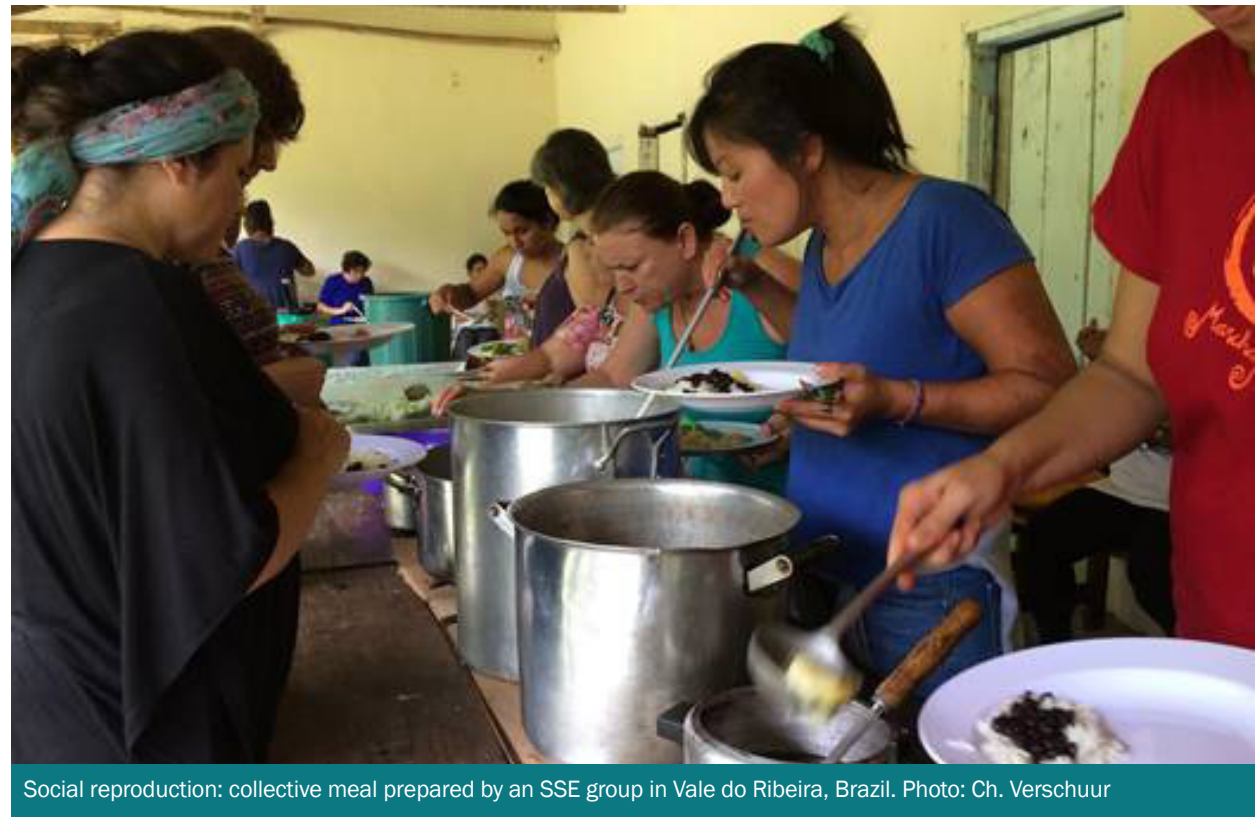

\section{SSE: A vehicle for the reorganization and revalorization of social reproduction}

These micro dynamics reflect the larger crisis of social reproduction that characterizes capitalist societies. Neoliberal policies and practices, in particular the overemphasis on economic growth, have severe implications for society and the environment. This economic model and the multiple crises accompanying it have shrunk investment in care, health and education; increased the precarity of the labour market; constrained social protection and rights; and degraded the natural environment-contributing, as a result, to poverty, inequalities and social discontent. In the cases studied, social and solidarity economy (SSE) practices have emerged in response to these conditions that characterize the "crisis of social reproduction" and the precarious livelihoods it produces.

SSE practices are embedded in local settings and are largely based on the needs, expectations, experiences and priorities of local participants. In the cases studied, these were women from marginalized communities. While social reproduction occupies a secondary position in capitalist societies, it is at the centre of all the (highly varied) SSE initiatives explored in the research. These initiatives simultaneously care for people and for the territory, ensuring the "enlarged reproduction of life" (that is, beyond mere subsistance [or biological reproduction], encompassing a morally acceptable minimum social quality of life as well). In so doing, they prioritize collective, social and at times environmental interests above material and individual ones. They deliver services (Argentina); strive towards environmental sustainability (Tamil Nadu; Brazil); ensure access to rights, such as the right to land (Bolivia; Brazil; Tamil Nadu), to food (Brazil; Karnataka; Tamil Nadu), to water (Brazil; Tamil Nadu) and to work (Karnataka); and promote worker's rights, such as social security and protection (Kerala; Karnataka; Argentina). The SSE practices studied also create new social relations, strengthen social ties among marginalized women and within the community, and, under certain conditions, change gender relations.

SSE practices also have the potential to reinstate "value" into women's productive and reproductive activities and thus revalorize the social reproductive sphere as a whole, which tends to be invisible. As a result, SSE, under certain conditions, has the potential to overcome the false dichotomy between production and social reproduction as separate spheres, which has long been critiqued by feminist scholars. The domestic workers' association studied in Kerala, for instance, is a movement for collectivizing and organizing socially and economically disadvantaged women to claim their right to be engaged in paid employment under restricted circumstances and dominant patriarchal norms, which prevent women from undertaking paid jobs outside the household.

In Karnataka, the Udupi fisherwomen's association not only engages with the state on women's behalf, safeguarding their right to work as fish sellers in a patriarchal capitalist environment that threatens this source of livelihood for women; it also defends women's economic and social rights, and strengthens social ties and solidarities among its members. It thus supports women both professionally and personally, with the solidarities forged between women serving various purposes both inside and outside the fish market. The women support each other in their everyday activities of managing the fish market and interacting with customers. Outside the market, solidarities between women enable support between families during times of need and crisis.

In the Argentina case study, the community associations of care workers guarantee access to rights such as food, education and recreation that the state does partially or does not guarantee. This process of de-familiarization and collectivization of care has led to the empowerment and increased politicization of marginalized women. It subsequently generated a transformation in their subjectivities and perception of themselves, their own work and their relationship vis-a-vis the state and society as a whole.

Although the impact on economic empowerment is still limited in the cases studied due to the low remuneration women receive for their work, these SSE practices have provided women with some material and symbolic advantages. SSE introduces alternative and to some extent counter-hegemonic practices and strategies that, under certain conditions, can be conducive to the reorganization of production and social reproduction and the empowerment of women. 
Associativity as a form of organization and practice, for instance, may-under certain conditions-contribute to the revalorization of women's work at the personal, familial, communal and political levels. At the personal level, associative practices create spaces of sociability outside of family relationships and the domestic sphere. These allow women to share their problems and receive moral support from other women. In the cases studied, such interactions broadened women's perspectives and helped change the way they perceive themselves and value their own work. These spaces gradually allowed women to generate a view of the social scenario that was different from the domestic order, allowing them to redefine their understanding of work. These processes further allowed women to reposition themselves inside the family. Many as a result gained more autonomy in the administration of their time and resources, and increased their bargaining power, while others even managed to stop situations of domestic violence. The tasks of care performed by women as a collective granted them further recognition in their communities and placed them in a position of power. Under certain conditions, women became increasingly politicized and positioned in a struggle with the state and market powers for recognition. Politicization, and the development of political subjectivities within SSE, were found to be key to the struggle for livelihoods, recognition and equity.

Training, and concrete actions for measuring and quantifying the value of women's work, also played an important role in the valorization process. For instance, in the case of domestic workers' associations in Kerala, the training undertaken by women led to the professionalization of domestic work; this professionalization contributed, in turn, to the recognition and subsequent revalorization of domestic work. Similar processes were observed in the associations of care workers in the Argentina case. These associations were perceived as places of personal growth and professionalization that, in turn, allowed women to redefine the way they perceived their own work and subsequently enhanced their self-esteem. In the case of producers' associations in Batallas (Bolivia), SSE initiatives promoted specialization and collective sale, centralized production, and improved quality of agricultural and dairy products. These practices have the potential to increase women's access to markets and income, thus contributing to the revalorization of their production and generating conditions that increase their self-esteem and, ultimately, their autonomy and rights.

The case study in Vale do Ribeira (Brazil), which centred on a network of women practicing agroecology, showed how SSE practices can contribute to revalorizing both monetary and non-monetary production. In this case, the collective organization of the women farmers together with the NGO supporting their network enabled them to set up a direct marketing network with responsible consumers, relying on the creation of trust and solidarity relations. Agroecology booklets were used to raise awareness of the approach and to record the quantity and monetary equivalent of consumed, sold, bartered and donated production, strengthening the women's position vis-a-vis the state and their partners, and increasing the recognition of the value of their work. These processes, and the women's collective organization to address obstacles they faced in terms of water and land management vis-a-vis the community and the state authorities, contributed to their autonomy and increased their politicization, and their bargaining power as result.

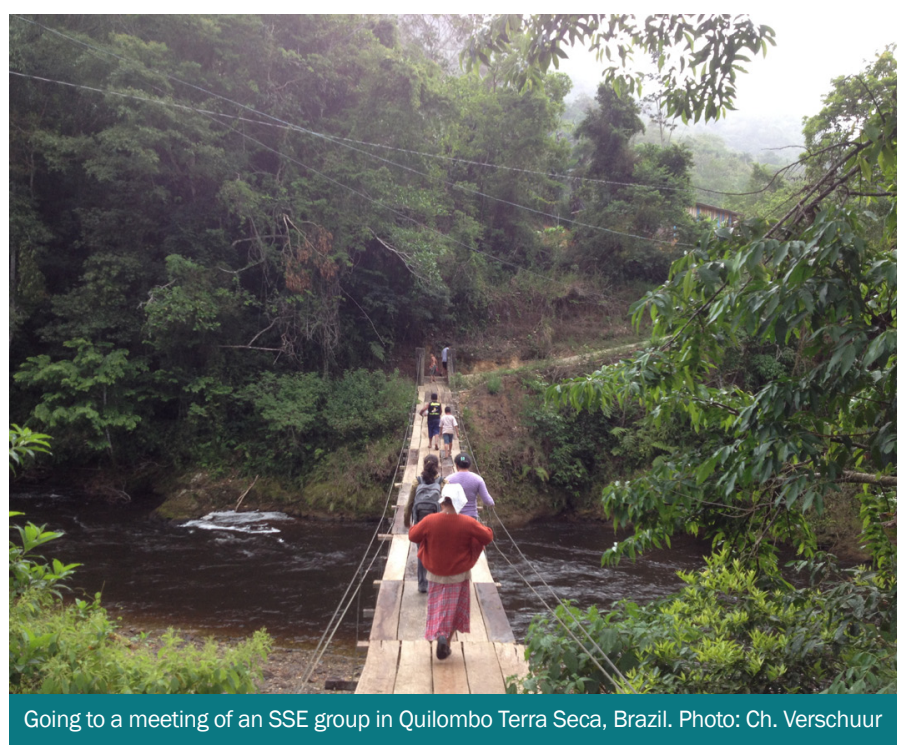

\section{Challenges to the revalorization of social reproduction}

The revalorization of social reproduction is a process marked with tensions and contradictions. A feminist analysis of SSE practices, as carried out in the project, sheds light on the constant struggle with the state, the capitalist market economy and patriarchal norms and practices.

In the Bolivian case study, for instance, issues related to the family or social reproduction remain outside the scope of associations with both men and women members. These tended to maintain a masculine discourse focused on the primary objective of increasing the value of production. In the case of community-based care associations in Argentina, care work remains feminized with a strong maternal approach, as most of those involved are women. Thus while, on one hand, the associations may contribute to the recognition of care work, they nevertheless trap women within a gendered role of care and motherhood where any increase of personal autonomy is rooted in gender-stereotyped tasks. In the case of the Udupi fisherwomen in Karnataka, while the association challenges the state and the free-market orientation, it does not challenge the underlying capitalist structure or patriarchal norms. Rather, it provides protection within the capitalist system, which, when combined with patriarchy, confines women to subsistence livelihoods while men's labour is better valued and considered worthy of being invested in.

Such tensions and contradictions with the capitalist market economy may also find their way into the associations' own structures and practices. Entrenched hierarchies and 
frustrations, for example, show up between women's personal objective of accumulation and the collective solidarity objective of redistribution. Within the dominant framework of the market, in which selling more generates higher incomes, solidarity associations are fragile and fraught with tensions. Moreover, women's predominance in solidarity economy practices often serves to enforce their role in collective activities, thus resulting in the paradox of associations that are meant to liberate women, actually entrenching them in voluntary or low-income work.

Limited state support can also hinder the development of SSE practices. This has been seen in all the cases studied. Conversely, state support characterized by gendered policies and programmes can reaffirm and reinforce the hierarchies embedded in capitalist societies, thus trapping women in gendered roles and limiting their emancipation. This raises the question of autonomy, but more so of the sustainability of SSE initiatives.

In the case of Vale do Ribeira, SSE groups depend to some extent on feminist NGOs that support their formation and development. Cuts in government funding to NGOs put the entire SSE project under pressure and force the search for new sources of funding. This raises the challenge of sustainability. The success of solidarity as an emancipation strategy depends on the ability to balance internal and external equity. In the case study, this means extending the network to new responsible consumers, creating new consumption groups, and building relations of trust and solidarity in which consumers take account of the needs of sustainable agriculture and the women's associations guarantee quality food at affordable prices to the urban working class. This process may in turn limit the dependence of women's associations on the state and contribute to expanding their number and networks. Nevertheless, while increasing the number of women's associations in a locality may contribute to strengthening women's political organization and autonomy, it may also put pressure on sales-creating competition that may challenge the value of solidarity. Open deliberation and discussion of these challenges within the women's associations are part of the process of fostering change in relations of production and reproduction.

The continuity of the SSE practices and women's associations studied is also conditioned by their capacity of being active in the territorial management in the communities where they are present. This is illustrated in the case of Vale do Ribeira where it encompasses, for example, reclaiming traditional knowledge, finding more diversified ways of trading their products, and including more and younger women. These SSE initiatives seek to create or reinforce reciprocity and strengthen a sense of community in rural districts characterized both by vulnerability in relation to big landowners and by patriarchal norms. The challenge is to connect women farmers' groups in the process of building a political subject capable of redefining the territory through management practices, agroforestry, agroecology, and also capable of engendering social relations which have as a horizon the sustainability of life.

\section{Recommendations}

- There is a need for public recognition of the value of women's work in SSE (and beyond) and there is a need to ensure decent work conditions for women active in SSE.

- Public policies in general and those related to SSE in particular should incorporate a gender perspective.

- Further research should examine conditions for ensuring SSE sustainability beyond state support; and how to address challenges to the revalorization of women's work.

Box 2: Project Team

Coordination

Coordinator: Christine Verschuur; Co-coordinator: Filipe Calvão; Research assistants: Yira Lazala, Laïs Meneguello Bressan (Graduate Institute of International and Development Studies / IHEID)

Country Research Teams

Argentina: Marisa Fournier and Erika Loritz (Universidad Nacional de General Sarmiento / UNGS)

Bolivia: Ivonne Farah, Gabriela Ruesgas and Fernanda Sostres (CIDES, Universidad Mayor San André); Isabelle Hillenkamp (Institut de recherche pour le développement / IRD-CESSMA)

Brazil: Miriam Nobre (Sempreviva Organização Feminista / SOF); Isabelle Hillenkamp (Institut de recherche pour le développement IRD-CESSMA)

India (Kerala): Rajib Nandi (Institute of Social Studies Trust) with inputs from Sheena Basheer and Sonia George

India (Tamil Nadu): Isabelle Guérin (Institut de recherche pour le développement / IRD-CESSMA); Govindan Venkatasubramanian and Santosh Kumar (Institut Français de Pondichéry) India (Karnataka): Kaveri Haritas (O.P. Jindal Global University)

\section{Partners}

Kalpana Karunakaran (Indian Institute of Technology Madras); Jean-Louis Laville (Centre National des Arts et Métiers / CNAM); Ibrahim SaÏd (UNRISD)

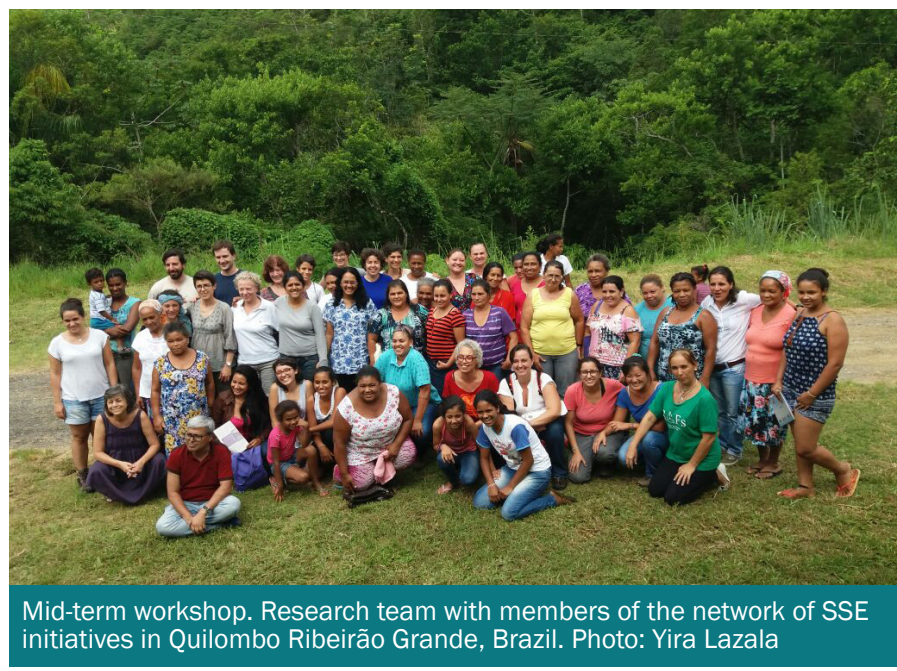

